\title{
WHAT FACTORS MATTER MOST FOR MOBILE LEARNING ADOPTION?
}

\author{
Sofia Moya and Mar Camacho \\ Universitat Rovira i Virgili, Spain
}

\begin{abstract}
This study investigates the interaction among factors affecting the effectiveness and consistency of frameworks for adoption and sustainable use of mobile learning. The research was designed according to a mixed-methods paradigm, including a literature review and a systematic review. A total of 362 factors were identified in the literature review of 75 studies. Twenty-five studies were included in the systematic review. The findings derive a five-discrete-dimension cluster that matter the most in isolation and as an orchestrate scenario: technological resources; digital literacy; pedagogical, behaviour, attitudes and ethics; and leadership. The findings could be useful to any schools which are thinking about introducing or amplifying mobile learning in their curriculum in order to prioritize and manage strategic initiatives.
\end{abstract}

\section{KEYWORDS}

Mobile Learning, Technology Integration, Leadership, Educational Strategies

\section{INTRODUCTION}

\subsection{Theoretical Framework}

The twenty-first century has brought a technological revolution which is continuously evolving toward powerful mobile and handled devices as well as intelligent software applications which are improving on our quality of lives (Fullan 2013, Camilleri 2016).

This digitization of the world is unstoppable, and this era is demanding digital talent. According to a 2016 Mckinsey study, "How to scale personalized learning", $22 \%$ of jobs are in vacancy because companies don't find the right candidates with the required skills. Tallinn, Estonia, held the first EU Digital Summit on September 2017. The summit brought together EU heads of state. It was a platform that launched high-level discussions on further plans for digital innovation with the aim of keeping Europe ahead of the technological curve. Since 2005, the European Commission's science Knowledge service, launched the Joint Research Canter (JRC), research on Learning and Skills for the Digital Era, with the aim to provide evidence-based policy support to the European Commission and the Member States on harnessing the potential of digital technologies to innovate education and training practices. Digital competency is included in the most relevant $21^{\text {st }}$-century skills models: enGauge $21^{\text {st }}$-century skills: Literacy in the Digital Age; Framework for $21^{\text {st }}$-Century Learning and Nurturing our Young for the Future: Competencies for the $21^{\text {st }}-$ Century (Adell, et al., 2013).

Affordability and usability are progressing worldwide at stunning speed. According to OECD quarterly broadband penetration report, mobile broadband penetration reached $97 \%$ penetration rate in the third quarter of 2016. Worldwide mobile subscriptions reached 7.5 billion, (Ewaldsson, 2016).. Mobile devices penetration's levels will continue growing and BYOD model seems likely to become the norm (Johnson et al., 2013).

A vast literature has proven multiple mobile learning positive benefits and impacts and has been recognized as one of the most influential technologies for education (Chee, et al., 2017; Crompton \& Burke, 2018; Hwang \& Wu, 2014; Liu et al., 2014; Mahdi, 2018; Pimmer et al., 2016; Sung et al., 2016; Virtanen et al., 2018; Wu, et al., 2012; Zheng, Li, Tian, \& Cui, Panpan, 2018; Islam \& Grünlund 2016). 
Frameworks to implement mobile learning have been developed focus on technology, content and pedagogical aspects, the purposes of which mainly were: designing and develop tools, analysis tools, evaluation tools and guiding tools (Ada, 2018; Al-Hunaiyyan, Bimba, Idris, \& Al-Sharhan, 2017; Crompton, 2017; Hwang, 2014; Kearney, Schuck, Burden, \& Aubusson, 2012; Koole, 2009; Lim Abdullah, Hussin, Asra, \& Zakaria, 2013; Ng \& Nicholas, 2013; Nordin, Embi, \& Yunus, 2010; Park, 2011; Rikala, 2015; Veerabhadram, de Beer, \& Conradie, 2012). However, adoption and sustainable use of mobile learning haven't unleashed its potential. Education remains steadfast and a considerable number of schools' reality is still quite analogical. The pedagogical use of this powerful learning methodology has not been maximized (Voogt, Knezek, Cox, Knezek, \& Brummelhuis, 2013; Vahtivuori-Hänninen \& Kynäslahti 2012; (Alrasheedi \& Capretz, 2015; Kopcha, 2012, Rikala, 2015; Nikolopoulou \& Gialamas, 2016; Stevenson, Hedberg, O’Sullivan, \& Howe, 2015). Moreover, when technology integration occurs, sustainability and efficiency use are challenges of mobile learning adoption (Keengwe, 2007; Sutton \& DeSantis, 2016; Hannah Oakman, 2016; Keengwe, Onchwari, \& Wachira, 2008).

Educational management has successfully adopted countless management tools, particularly those oriented towards strategic management processes. Mobile learning adoption has been considered as a strategic process that could be managed using management tools (Kettunen, 2007; Wong, 2005; Ng \& Nicholas, 2013).

Critical factors are crucial in the organization's strategies, Michel Porter, (1996). "Critical factors can be viewed as those activities and constituents that must be addressed in order to ensure its successful accomplishment and acceptance by the various stakeholders "(Goyal, Purohit, \& Bhagat, 2010, p.2). Managing factors affecting strategic management is part of the process and shape the efficiency and consistency (Glueck, Business policy and strategic management, 1980; Mintzberg, 1995; Porter, 1996).

\subsection{Purpose of the Study}

The objective of this study is to identify and evaluate the critical factors that shaped the adoption and sustainable use of mobile learning. Identifying the main factors influencing the mobile learning and how can enhance or impede effective adoption and sustainable use. Thus, the research question to be answered in this paper is: Which factors determine the success of mobile learning adoption and sustainable use?. The two specific research questions driving this study are.

(1) What are the key success factors in integrating mobile learning within education?

(2) How key factors affecting mobile learning can be grouped in a communal hierarchical taxonomy?

\section{RESEARCH DESIGN}

Explanatory sequential design (Creswell 2012) was used to direct different methods and mixed collection data tools were employed with the objective to triangulate and validate research and prove evidence. Table 1 illustrates the research design.

Table 1. Research Design

\begin{tabular}{|c|c|c|c|}
\hline $\begin{array}{l}\text { Research } \\
\text { pursued }\end{array}$ & Research objective & $\begin{array}{l}\text { Sample/ } \\
\text { Participants }\end{array}$ & $\begin{array}{l}\text { Data collection } \\
\text { method }\end{array}$ \\
\hline Explanatory & $\begin{array}{l}\text { Develop an initial understanding of key factors affecting } \\
\text { mobile learning adoption. RQ1. What are the key success } \\
\text { factors in integrating mobile learning within education? }\end{array}$ & $\begin{array}{l}\mathrm{N}=75 \text { studies } \\
\mathrm{N}=\quad 362 \quad \text { Factors } \\
\text { identified }\end{array}$ & Literature review \\
\hline Explanatory & $\begin{array}{l}\text { To collect evidence regarding the cause-and-effect of the } \\
\text { most common barriers and enablers of mobile learning. } \\
\text { Identify the main categories grouping factors affecting } \\
\text { mobile learning adoption in secondary schools. Gather } \\
\text { information needed to design the expert judgment. RQ2 } \\
\text { How key factors affecting mobile learning can be } \\
\text { grouped in a communal hierarchical taxonomy? }\end{array}$ & $\mathrm{N}=27$ studies & Systematic review \\
\hline
\end{tabular}


Search literature was based in concept-centric (Okoli \& Schabram, 2010; Webster \& Watson, 2002). For literature reviews conducted in relation to education, the Web of Science database has been recommended by several previous studies (Fu \& Hwang, 2018). With the objective to identify the main factors affecting mobile learning adoption, both mobile learning and strategic management critical factors were included in the research. The expressions ("mobile learning" OR "ubiquitous learning" OR "blended learning" OR "M-learning" OR "B-learning" OR "mobile devices" OR "strategic management" OR "strategic process" OR "strategic planning") AND ("factors") were used. The research process initially yielded 242 publications. Results were filtered by timespan between 2008 and 2018, resulting in 203 studies. A total of 75 studies were selected based on titles and reading its abstract and keywords revised, refined and article grouping was adjusted and summarize in a meta-data and concept matrix.

A systematic review (Hemingway \& Brereton, 2009) approach was performed in this study to answer the second research question directing this study with the goals of providing an impartial synthesis, summarize and generalize the relevant knowledge, trends as well as to identify the main categories.

Based on the prior literature review research, the following inclusion and exclusion criteria were applied: categorization or grouping was among the key variables of the study and studies must have been published between 2008 and 2019. A total of 35 full-texts were identified as eligible for the review and were comprehensively analysed by two of them. Finally, 27 studies were included in the systematic review. Figure 1 shows the data search and collection process. The 27 studies included in this analysis are identified with an asterisk in the bibiliography.
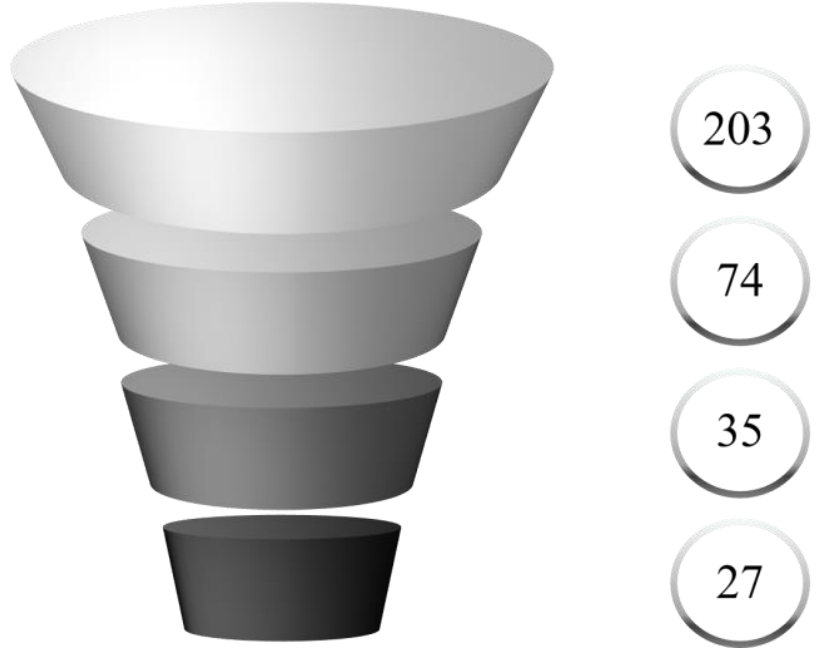

Keywords: mobile learning or strategic management and factors Source: Web of Science Timespan: 2008-2018

Figure 1. Diagram of the systematic review search process

\section{RESULTS}

\subsection{Factors Affecting Mobile Learning Adoption}

There are numerous mobile learning definitions, most of them highlight the core characteristics such as mobility, ubiquity, interaction, learner-centred approach, formative assessment, collaborative sharing and personalization (Osman, El-Hussein, and Cronje, 2010; Crompton, Muilenburg and Berge,2013; Peng et al. 2009; Peters 2009; Cochrane \& Bateman, 2010; Teoh, 2011 Jahnke and Kumar 2014; Alrasheedi \& Capretz, 2015; Thinley et al. 2014; Cochrane et al. 2013, Kean et al. 2013). For the purposes of this study, we will define mobile learning as the art of using mobile technologies to empower and enhance learning experiences (Rikala, 2016).

Literature highlights isolated recurrent factors affecting strategic management, and mobile learning. Most of the studies analysed were focused on the perceived performance or learning outcomes. A significant number of the studies analysed were focused on students' or teachers' perceptions. Based on the literature 
review of 75 studies, 362 different factors have been identified. The most cited factor is communication cited in 10 studies, followed by leadership, highlighted in 6 studies, assimilation with curriculum and institutional support were cited in five and four studies respectively.

\subsection{Taxonomies of Factors Affecting Mobile Learning Adoption}

There is significantly consistence amount grouping the factors affecting strategic management in two big categories. On one hand, hard factors, including those impacting company performances in a way that companies can reasonably handle, manage and measure. This category includes factors such as technological resources, company's structure, managerial skills, strategy and organization. Some authors call this group hard factors. Hard elements are easier to define or identify and management can directly influence them (Peters \& Waterman, 1982). Other frameworks call this category performance factors (Dewar et al., 2011). Other studies group in a similar way called this category independent variables (Humaidi, Anuar, \& Azzah Said, 2017). Some frameworks identify this category as hard or institutional factors (Li, et al., 2008).

On the other hand, soft factors, this second category includes the factors affecting the company's soul, culture and organizational behaviour.in their three main areas: individual, group and organization. This category has often been identified as soft factors. "Soft" elements can be more difficult to describe and are less tangible and more influenced by culture (Peters \& Waterman, 2012). Other studies identify this category as health (Dewar, et al., 2011). Other studies group in a similar way called this category dependent variables (Humaidi, Anuar, \& Azzah Said, 2017). This category has also been identified as soft or people-oriented (Li, et al., 2008). Table 2 summarizes the categories of factors affecting strategic management.

Table 2. Categories of factors affecting strategic management process: frameworks and studies

\begin{tabular}{|c|c|c|c|}
\hline Category & Study working & Framework & Study \\
\hline \multirow[t]{5}{*}{ Hard } & Hard & $7 \mathrm{~S}$ framework & Peters \& Waterman (1982) \\
\hline & Hard & $8 \mathrm{~S}$ framework & Higgings (2005) \\
\hline & Performance & 5 As framework & Dewar et al. (2011) \\
\hline & Independent & $\begin{array}{l}\text { Knowledge Project Management } \\
\text { Performance Assessment }\end{array}$ & Humaidi, Anuar \& Azzah Said (2017) \\
\hline & Hard & $\begin{array}{l}\text { A framework of strategy } \\
\text { implementation research }\end{array}$ & Li, Guohui \& Martin, (2008) \\
\hline \multirow[t]{5}{*}{ Soft } & Soft & $7 \mathrm{~S}$ framework & Peters \& Waterman (1982) \\
\hline & Soft & $\begin{array}{l}\text { A framework of strategy } \\
\text { implementation research }\end{array}$ & Li, Guohui \& Martin, (2008) \\
\hline & Soft & $8 \mathrm{~S}$ framework & Higgings (2005) \\
\hline & Health & 5 As framework & Dewar et al. (2011) \\
\hline & Dependent & $\begin{array}{l}\text { Knowledge Project Management } \\
\text { Performance Assessment }\end{array}$ & Humaidi, Anuar \& Azzah Said (2017) \\
\hline
\end{tabular}

Featured in the book by former McKinsey consultants Thomas J. Peters and Robert H. Waterman, Mc Kinsey developed a management framework that maps a constellation of interrelated factors that influence an organization's ability to change. The McKinsey "7S" framework involves seven interdependent factors which are categorized as either "hard" or "soft" elements. "Hard" elements are easier to define or identify and management can directly influence them: Strategy, Structure and Systems. "Soft" elements, are more difficult to describe, and are less tangible and more influenced by culture: Shared values, Skills, Style and Staff. This framework that has persisted over the years according to McKinsey Quarterly report, March 2008. In 2005, Higgins adapted the framework and sets up an " $8 \mathrm{~S}$ " framework of strategy implementation, including strategy and purposes structure, resources, shared values, style, staff, systems and processes, and strategic performance.

Li, Guohui and Eppler (2008), identified nine recurring factors affecting strategy implementation. They divided those nine factors into three categories; soft, hard and mixed factors. Soft factors (or people-oriented factors) include the people or executors of the strategy; communication; relationship with different business units; consensus; tactics and commitment to the strategy. Strategy formulation factor is considered a mixed factor containing hard and soft elements (Li, et al., 2008). 
The McKinsey "5As" framework, 2011, highlights health as well as performance as the key to sustaining excellence. The framework is based on a structured process characterized as " $5 \mathrm{As}$ ": aspire, assess, architect, act and advance. For each stage, there are frameworks for performance and health that enable leaders to manage both with the same rigour and discipline. Performance five stages are related to strategic objectives, capacity platform, the portfolio of initiatives, delivery model and continuous improvement, in terms of health, the five stages are health essentials, the discovery process, influence model, change the engine and central leadership (Dewar, et al., 2011).

Humaidi, Anuar and Azzah, developed a conceptual framework grouping factors affecting project management. The framework draws on the bases of T.M. Qureshi. A. S. Warraich and S.T. Hijazi, 2009, included six independent variables (leadership, staff, policy \& strategy, partnership \& resources, project life-cycle management process and key performance indicators) and one dependent variable (project management performance). They added knowledge as a factor that can cause management performance. The framework was named Knowledge Project Management Performance Assessment (KPMPA) (Humaidi, et al., 2017).

Most of the 27 studies analysed in the systematic review applied a specific model to test user attitude and intention to adopt new technologies. Several models have been identified, including: the theory of reasoned action (TRA) (Fishbein and Ajzen 1975), the technology acceptance model (TAM) (Davis 1989), the theory of planned behaviour (TPB) (Ajzen 1991), and the Unified Theory of Acceptance and Use of Technology (UTAUT) (Venkatesh, Morris, Davis \& Davis, 2003).

Among the different models, TAM appears to be one of the most used in the studies included in this research. Technology Acceptance Model (TAM) (Davis, 1989) consists of five main elements: perceived usefulness, perceived ease of use, attitude toward using, behavioural intention and actual system use. Perceived usefulness refers to "the degree to which a person believes that using a particular system would enhance his or her job performance"; and perceived ease of use defined as "the degree to which a person believes that using a particular system would be free from effort" (Davis, 1989). Both of them are impacted by external variables. Technology Acceptance Model is shown in Figure 2.

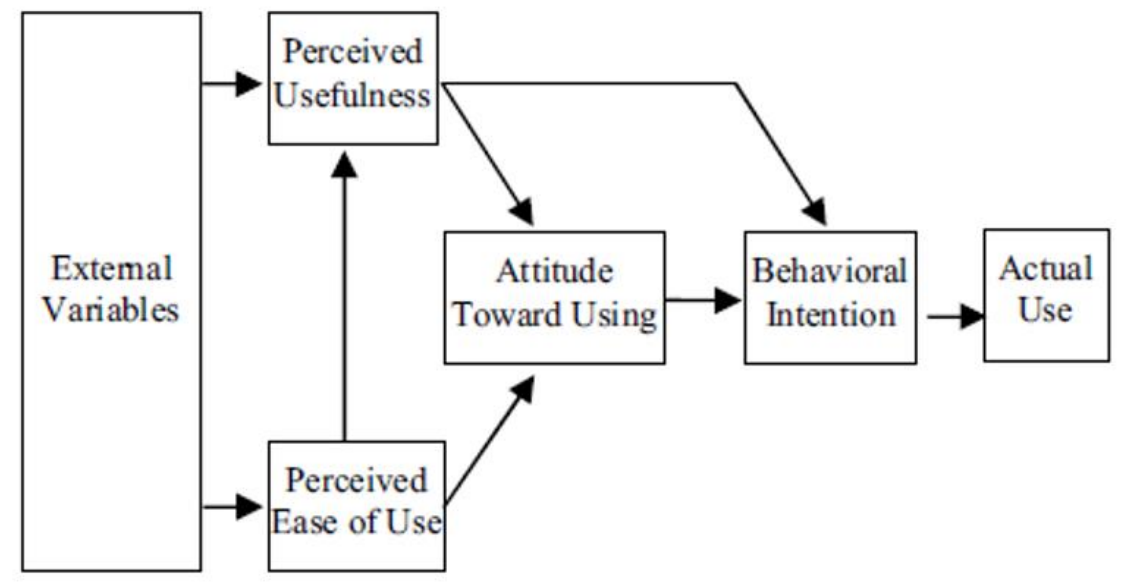

Figure 2. Diagram of the systematic review search process

A parallel can be made here with the main categories of factors affecting strategic management analysed above. Variables impacting perceived ease to use are those affecting "the degree to which a person believes that using a particular system would be free from effort" (Davis, 1989).

Based on strategic management factors classification described above (hard and soft); TAM theory classification (perceived easy to use and perceived usefulness); and Teoh (2011) and Alrashedi et al. (2015) studies; five categories were used to analyse the 27 studies included in the systematic review. Three categories of factors (technological resources, pedagogical and digital literacy) derived from hard factors and factors affecting the perception of easy to use. The other two categories (Behaviours, attitudes and ethics; and leadership) were considered soft factors or factors affecting the perception of usefulness in TAM theory. Table 3 shows the five categories of factors affecting mobile learning adoption and the number of mentions in the 27 studies included in this systematic review. 
Table 3. Dimension and Categories of factors affecting mobile learning adoption

\begin{tabular}{l|lr}
\hline Dimension & Category & $\begin{array}{l}\text { Recurrence in the } \\
\text { systematic review }\end{array}$ \\
\hline Hard & & $\mathbf{7 2}$ \\
\hline & Technological resources & 17 \\
\hline & Pedagogical & 39 \\
\hline Soft & Digital literacy & 16 \\
\hline & & $\mathbf{5 2}$ \\
\hline & Behaviours, attitudes and ethics & 23 \\
\hline & Leadership & 29 \\
\hline & Total general & 124 \\
\hline
\end{tabular}

The first category is related to technological resources, it includes factors such as technological infrastructure, navigation, internet connexion, mobile tools, level of integration, technical support, student-device ratio or hardware. Other names with which this category is identified are: technological factors (Olafsen, 2005; Goyal, Purohit, \& Bhagat, 2010; Mahdi, 2017; Sharples 2013; Hao, Dennen, \& Mei, 2017); hard factors (Dublin, 2004); non-human factors (Spector, 2013) and technological infrastructures (Tay, Liam \& Lim 2013).

The Second category encompasses pedagogical factors such as classroom integration, adaptability of the course, assessment, availability of content and software, critical thinking, develop thinking, time management, recognition of informal learning, define target learner groups for m-Learning; teaching preparation, solving problems, design approach, gamification, virtual environments, or customization. Most authors call this category pedagogical factors, pedagogical integration, learning-related or learner's requirement (Graf \& Caines, 2004; Olivier, 2005; Goyal, Purohit, \& Bhagat, 2010; Cochrane and Bateman, 2010; UNESCO, 2011; Johnson, 2011; Yoo, Han, \& Huang, 2012; Mahdi, 2017; Hao, Dennen, \& Mei, 2017; Ekberg \& Gao, 2017).

A third category refers to educational community's mobile learning skills or digital literacy, to this category belong the following factors: teacher's digital knowledge, training, student's knowledge, teacher's and student's digital competency, teacher's practices and digital assessment knowledge. Some studies called this category of digital literacy (Johnson et al. 2011; Goyal, Purohit, \& Bhagat, 2010). Tay, Liam, and Lim (2013) called this dimension of professional development. Yeap et al. (2016) referred to this category as "instructor readiness". Hargreaves and Fullan (2012) emphasize teacher's role in the use of technology for professional learning. Training has pointed out as a crucial factor (Abu Al-Zur \& Qablan, 2011; Al Sharija, James \& Waters, 2012).

The fourth category integrates human-related factors, focus on individual behaviours, attitudes and ethics. Often labelled as soft or human factors category (Dublin, 2004; Spector, 2013; Hao, Dennen, \& Mei (2017), named this category personal and social factors. Yoo, Han, \& Huang (2012), called motivational factors it also includes behaviours and attitudes, teacher's attitudes are decisive in the successful integration of m-learning in teaching. The resistance to change factors represents a significant portion of this category (Spector, 2013; Mercader, 2018).

The fifth category integrates human-related factors, affecting organization and groups, highlighting leadership as the most cited. In educational management, the importance of articulating organizational values is widely acknowledged. Tay, Liam, and Lim (2013) referred to this category as school leadership, Ekberg \& Shang (2017) named support from school leadership. Ekberg \& Gao, (2017) in their framework place a variable called school leadership.

\section{CONCLUSIONS}

The purpose of this study was to conduct an analysis of the factors that affect most mobile learning adoption. The study had employed two different research methods to gather evidence of the main categories of factors. A total of 362 different factors were found. Factors affecting mobile learning adoption were grouped based on two dimensions: hard and soft. Hard dimension relates to categories of factors that impacting learning performances in a way that institutions can reasonably handle, manage and measure. This dimension includes three categories: technological resources, digital literacy and pedagogical factors. The second dimension is 
soft and represents the categories of factors affecting the institution's soul and people's attitudes. Two categories derivate from this dimension: behaviours, attitudes and ethics; and leadership.

Future studies might confirm the proposed classification as well as prioritize the different categories and factors.

The findings could be useful to any schools which are thinking about introducing or amplifying mobile learning in their curriculum in order to prioritize and manage strategic initiatives.

\section{REFERENCES}

Ada, M. B. (2018). Using design-based research to develop a Mobile Learning Framework for Assessment Feedback. Research and Practice in Technology Enhanced Learning, 13(1), 3.

Aguti, B., Wills, G. B., \& Walters, R. J. (2014). An evaluation of the factors that impact on the effectiveness of blended e-learning within universities. In Information Society (i-Society), 2014 International Conference on (pp. 117-121). IEEE.

Alrasheedi, M., \& Capretz, L. F. (2018). Determination of critical success factors affecting mobile learning: a meta-analysis approach. ArXiv Preprint ArXiv:1801.04288.

Al-Sharhan, S., Al-Hunaiyyan, A., \& Al-sharah, H. (2010). A new efficient blended e-learning model and framework for K12 and higher education: Design and implementation success factors. In Digital Information Management (ICDIM), 2010 Fifth International Conference on (pp. 465-471). IEEE.

Bower, M., Dalgarno, B., Kennedy, G. E., Lee, M. J., \& Kenney, J. (2015). Design and implementation factors in blended synchronous learning environments: Outcomes from a cross-case analysis. Computers \& Education, 86, $1-17$.

Cochrane, T. D. (2010). Exploring mobile learning success factors. ALT-J, 18(2), $133-148$. https://doi.org/10.1080/09687769.2010.494718

Ekberg, S., \& Gao, S. (2018). Understanding challenges of using ICT in secondary schools in Sweden from teachers' perspective. The International Journal of Information and Learning Technology, 35(1), 43-55.

Fu, Q.-K., \& Hwang, G.-J. (2018). Trends in mobile technology-supported collaborative learning: A systematic review of journal publications from 2007 to 2016. Computers \& Education, 119, 129-143. https://doi.org/10.1016/j.compedu.2018.01.004

Gao, Shang, Krogstie, John, \& Siau, Keng. (2011). Developing an instrument to measure the adoption... - Google Académico. Retrieved 9 December 2018, from

Purohit, S., \& Bhagat, M. (2010). Factors that affect information and communication technology usage: A case study in management education. Journal of Information Technology Management, 21(4), 38-57.

Hamidi, H., \& Chavoshi, A. (2018). Analysis of the essential factors for the adoption of mobile learning in higher education: A case study of students of the University of Technology. Telematics and Informatics, 35(4), 1053-1070.

Hao, S., Dennen, V. P., \& Mei, L. (2017). Influential factors for mobile learning acceptance among Chinese users. Educational Technology Research and Development, 65(1), 101-123.

Hemingway, P., \& Brereton, N. (2009). What is a systematic review. What Is.

Kukulska-Hulme, A. (2008). Human factors and innovation with mobile devices. In Handbook of research on digital information technologies: innovations, methods, and ethical issues (pp. 392-403). IGI Global.

Lim Abdullah, M. R. T., Hussin, Z., Asra, B., \& Zakaria, A. R. (2013). MLearning scaffolding model for undergraduate English language learning: bridging formal and informal learning. TOJET: The Turkish Online Journal of Educational Technology, 12(2), 217-233.

Liu, Y., Li, H., \& Carlsson, C. (2009). Exploring the factors driving m-learning adoption. AMCIS 2009 Proceedings, 178.

López-Hernández, F. A., \& Silva-Pérez, M. M. (2016). Factores que inciden en la aceptación de los dispositivos móviles para el aprendizaje en educación superior.

Lu, X., \& Viehland, D. (2008). Factors influencing the adoption of mobile learning. ACIS 2008 Proceedings, 56.

Mahdi, H. S. (2017). Effectiveness of Mobile Devices on Vocabulary Learning: A Meta-Analysis. Journal of Educational Computing Research, 56(1), 134-154. https://doi.org/10.1177/0735633117698826

Mercader Juan, C. (2018). Las tecnologías digitales en la docencia universitaria. Barreras para su integración (PhD Thesis). Universitat Autònoma de Barcelona.

Ng, W., \& Nicholas, H. (2013). A framework for sustainable mobile learning in schools. British Journal of Educational Technology, 44(5), 695-715. 
Nordin, N., Embi, M. A., \& Yunus, M. M. (2010). Mobile Learning Framework for Lifelong Learning. Procedia - Social and Behavioural Sciences, 7, 130-138. https://doi.org/10.1016/j.sbspro.2010.10.019

Okoli, C., \& Schabram, K. (2010). A guide to conducting a systematic literature review of information systems research.

Olafsen, R. N., \& Cetindamar, D. (2005). E-learning in a competitive firm setting. Innovations in Education and Teaching International, 42(4), 325-335.

Park, Y. (2011). A pedagogical framework for mobile learning: Categorizing educational applications of mobile technologies into four types. The International Review of Research in Open and Distributed Learning, 12(2), 78-102.

Rikala, J. (2015). Designing a mobile learning framework for a formal educational context. Jyväskylä Studies in Computing, (220).

Sabah, N. M. (2016). Exploring students' awareness and perceptions: Influencing factors and individual differences driving m-learning adoption. Computers in Human Behaviour, 65, 522-533.

Sarrab, M., Al-Shihi, H., \& Shibli, I. N. S. A. (2017). Mobile learning key influencing factors adoption based on analytic hierarchy process. International Journal of Information and Decision Sciences, 9(4), 387-404.

Spector, J. M. (2013). Emerging educational technologies and research directions. Journal of Educational Technology \& Society, 16(2).

Stacey, E., \& Gerbic, P. (2008). Success factors for blended learning. Hello! Where Are You in the Landscape of Educational Technology? Proceedings Ascilite Melbourne 2008, 964-968.

Tay, L. Y., Lim, S. K., \& Lim, C. P. (2013). Factors affecting the ICT integration and implementation of one-to-one computing learning environment in a primary school-A sociocultural perspective. In Creating Holistic Technology-Enhanced Learning Experiences (pp. 19-37). Springer.

Teoh, K.-K. (2011). An examination of critical success factors in the implementation of ePortfolios in universities. Journal of Academic Language and Learning, 5(2), A60-A72.

UNESCO, N. (2011). UNESCO Mobile Learning Week Report.

Yadegaridehkordi, E., Iahad, N. A., \& Baloch, H. Z. (2013). Success factors influencing the adoption of M-learning. International Journal of Continuing Engineering Education and Life Long Learning, 23(2), 167-178.

Yeap, J. A., Ramayah, T., \& Soto-Acosta, P. (2016). Factors propelling the adoption of m-learning among students in higher education. Electronic Markets, 26(4), 323-338. 